\title{
Morphological Correlates of Corticosteroid-Induced Changes in Prefrontal Cortex-Dependent Behaviors
}

\author{
João J. Cerqueira, ${ }^{1}$ José M. Pêgo, ${ }^{1}$ Ricardo Taipa, ${ }^{1}$ João M. Bessa, ${ }^{1}$ Osborne F. X. Almeida, ${ }^{2}$ and Nuno Sousa ${ }^{1}$ \\ ${ }^{1}$ Life and Health Sciences Research Institute, School of Health Sciences, University of Minho, 4710-057 Braga, Portugal, and ${ }^{2}$ Neuroadaptations Group, Max \\ Planck Institute of Psychiatry, 80804 Munich, Germany
}

Imbalances in the corticosteroid milieu have been implicated in several neuropsychiatric disorders, including depression and schizophrenia. Prefrontal cortex (PFC) dysfunction is also a hallmark of these conditions, causing impairments in executive functions such as behavioral flexibility and working memory. Recent studies have suggested that the PFC might be influenced by corticosteroids released during stress. To test this possibility, we assessed spatial working memory and behavioral flexibility in rats submitted to chronic adrenalectomy or treatment with corticosterone $(25 \mathrm{mg} / \mathrm{kg}$ ) or the synthetic glucocorticoid dexamethasone (300 $\mu \mathrm{g} / \mathrm{kg})$; the behavioral analysis was complemented by stereological evaluation of the PFC (prelimbic, infralimbic, and anterior cingulate regions), the adjacent retrosplenial and motor cortices, and the hippocampal formation. Dexamethasone treatment resulted in a pronounced impairment in working memory and behavioral flexibility, effects that correlated with neuronal loss and atrophy of layer II of the infralimbic, prelimbic, and cingulate cortices. Exposure to corticosterone produced milder impairments in behavioral flexibility, but not in working memory, and reduced the volume of layer II of all prefrontal areas. Interestingly, adrenalectomy-induced deleterious effects only became apparent on the reverse learning task and were not associated with structural alterations in the PFC. None of the experimental procedures influenced the morphology of retrosplenial or motor cortices, but stereological measurements confirmed previously observed effects of corticosteroids on hippocampal structure. Our results describe, for the first time, that imbalances in the corticosteroid environment can induce degeneration of specific layers of the PFC; these changes appear to be the morphological correlate of corticosteroid-induced impairment of PFC-dependent behavior(s).

Key words: corticosterone; dexamethasone; adrenalectomy; neuroendocrine regulation; working memory; stereology

\section{Introduction}

Damage to the prefrontal cortex (PFC) in humans impairs behavioral flexibility (Milner et al., 1985; Colvin et al., 2001), decision making (Bechara et al., 2000; Manes et al., 2002), and planning (Bechara et al., 1996; Muller et al., 2002). In rats, the medial PFC ( $\mathrm{mPFC}$ ) is homologous to the dorsolateral PFC in primates (Vogt et al., 2004). Lesions in this area typically disrupt executive functions, including response inhibition (Li and Shao, 1998; Salazar et al., 2004), temporal organization of behavior (Hannesson et al., 2004; Hata and Okaichi, 2004), and working memory (Shaw and Aggleton, 1993; Joel et al., 1997; Kesner, 2000). Deficits in working memory, associated with prefrontal cortical dysfunction, are a hallmark of several neuropsychiatric disorders, including depression, Parkinson's disease, and schizophrenia (Lewis et al., 2004; Monchi et al., 2004; Rogers et al., 2004; Shad et al., 2004). Both stress and hypersecretion of corticosteroids have been causally implicated in depression and schizophrenia (Altamura et al., 1999; Corcoran et al., 2002; Barden, 2004; Ryan et al., 2004).

Received Jan. 5, 2005; revised July 14, 2005; accepted July 14, 2005.

Part of this work was supported by an Acções Integradas Luso-Alemãs grant from the German Academic Exchange Service and the Portuguese Rectors' Conference.

Correspondence should be addressed to Nuno Sousa, Escola de Ciências da Saúde, Complexo Pedagógico II Piso3, Universidade do Minho, Campus de Gualtar, 4710-057 Braga, Portugal. E-mail: njcsousa@ecsaude.uminho.pt. D0I:10.1523/JNEUROSCI.1598-05.2005

Copyright $\odot 2005$ Society for Neuroscience $\quad$ 0270-6474/05/257792-09\$15.00/0
These observations complement recent evidence that stress per se (Mizoguchi et al., 2000) or adrenocorticosteroids (CoburnLitvak et al., 2003; Roozendaal et al., 2004) can profoundly influence PFC-dependent cognitive processes and that impaired glucocorticoid-negative feedback on the hypothalamo-pituitaryadrenal (HPA) axis may involve the PFC and hippocampus (Diorio et al., 1993; Sullivan and Gratton, 2002; Mizoguchi et al., 2003).

Corticosteroid actions in the brain are mediated by mineralocorticoid (MR) and glucocorticoid (GR) receptors (Reul and de Kloet, 1985). In addition to the hippocampus, a region characterized by a high density of MR and GR and with an established role in the physiological and behavioral adaptation to stress (de Kloet et al., 1998; Reul et al., 2000), the mPFC has a rich population of corticosteroid receptors (Chao et al., 1989; Herman, 1993; Patel et al., 2000), which become activated during stress (Cullinan et al., 1995; Figueiredo et al., 2003). Changes in neuronal morphology and survival are thought to, at least partly, underpin corticosteroid-induced alterations in hippocampal function (Sousa and Almeida, 2002). Recent studies from two laboratories have demonstrated that chronic treatments with either corticosterone or restraint stress induce a remodeling of apical dendrites of layer II/III pyramidal neurons in the $\mathrm{MPFC}$, such that there is greater proximal branching, whereas spine density is reduced (Wellman, 2001; Cook and Wellman, 2004; Radley et al., 2004, 
2005). Although alterations of the corticosteroid milieu have also been reported to result in impaired spatial working memory, as measured in the T-maze (Mizoguchi et al., 2000, 2004) and Y-maze (Coburn-Litvak et al., 2003), a direct structure-function relationship has not yet been established. The present study was intended to fill this gap by parallel evaluation of cognitive performance and PFC morphology. Briefly, a detailed stereological analysis was conducted on the mPFC of rats whose working memory and behavioral flexibility had been tested during exposure to different corticosteroid environments. The latter were induced by adrenalectomy (leaving the animals corticosteroidfree) or by chronic treatment with either an endogenous corticosteroid [corticosterone (CORT)] or the synthetic GR-selective agonist dexamethasone (DEX).

\section{Materials and Methods}

Animals and treatments

Experiments were conducted in accordance with local regulations (European Union Directive 86/609/EEC) and National Institutes of Health guidelines on animal care and experimentation.

Adult male Wistar rats (Charles River Laboratories, Barcelona, Spain) were housed in groups of three to four under standard laboratory conditions (lights on from 8:00 A.M. to 8:00 P.M.; room temperature, $22^{\circ} \mathrm{C}$; ad libitum access to food and drink). Treatments were initiated when animals were 8 weeks of age and continued over a period of 4 weeks, after which behavioral tests were conducted. All drugs were from Sigma (St. Louis, MO). To compare the influence of the corticosteroid milieu, rats were assigned to one of four treatment groups $(n=10)$ : (1) Control $(\mathrm{CON})$, receiving daily subcutaneous injections of sesame oil (vehicle) but otherwise maintained as described above; (2) adrenalectomized (ADX) (performed under pentobarbital anesthesia), receiving daily subcutaneous injections of vehicle and maintained on a $0.9 \%$ saline drinking solution; (3) CORT-treated, receiving one daily subcutaneous injection of CORT ( $25 \mathrm{mg} / \mathrm{kg}$ in sesame oil); and (4) DEX-treated, receiving a daily subcutaneous injection of DEX (300 $\mu \mathrm{g} / \mathrm{kg}$ dissolved in sesame oil containing $0.01 \%$ ethanol). All injections were administered $1 \mathrm{~h}$ before "lights out."

Treatments continued over a period of 4 weeks when blood (tail venipuncture) samples were collected for basal measurements of CORT ( $1 \mathrm{~h}$ after "lights on") just before behavioral testing (3:00 P.M.) and $1 \mathrm{~h}$ after lights out. Serum CORT levels were subsequently measured by radioimmunoassay (MP Biomedicals, Costa Mesa, CA).

Body weights were recorded on a weekly basis throughout the study as an indication of treatment efficacy; postmortem adrenal and thymus weights also provided information on treatment efficacy.

\section{Behavioral testing}

Behavioral tests were conducted in a circular black tank $(170 \mathrm{~cm}$ diameter) filled to a depth of $31 \mathrm{~cm}\left(\right.$ at $\left.22^{\circ} \mathrm{C}\right)$ with water colored with a black nontoxic dye (Jazz Gloss Tempera black ink from Van Aken International, Rancho Cucamonga, CA) and placed in a dimly lit room with extrinsic clues. The tank was divided into imaginary quadrants and had a black platform (12 cm diameter, $30 \mathrm{~cm}$ height) placed in one of them. Data were collected using a video camera fixed to the ceiling and connected to a video tracking system (Viewpoint, Champagne au Mont d'Or, France).

Working memory task. The test used was described by Kesner (2000) as a test of PFC function: its goal is to assess the ability of rats to learn the position of the hidden platform and to keep this information on-line during four consecutive trials. The working memory test, a modification of the spatial reference memory test (Morris, 1984), consisted of $4 \mathrm{~d}$ of acquisition ( 4 trials/d). On each trial day, the position of the platform was kept constant, but the position was varied on each successive day such that all four quadrants were used. Rats were placed, facing the wall of the maze, at a different starting point [north $(\mathrm{N})$, east $(\mathrm{E})$, south $(\mathrm{S})$, or west (W)] at the start of each of the four daily trials. A trial was considered ended when the rat escaped onto the platform; when this escape failed to occur within $120 \mathrm{~s}$, the animal was gently guided to the platform, and an escape latency of $120 \mathrm{~s}$ was recorded for that trial. Rats were allowed to spend $30 \mathrm{~s}$ on the escape platform before being positioned at a new starting point. Length of the path described and time spent to reach the platform (escape latency) were recorded in the consecutive trials.

Reverse learning task. After the working memory procedure (days $1-4$ ), animals were tested for an additional $2 \mathrm{~d}$ (days 5-6), when the platform remained in the same quadrant as that on day 4 , to ensure that the animals had correctly learned the position of the platform before assessment of reversal learning (de Bruin et al., 1994). All of the remaining procedures were similar to the ones described for the working memory task. On day 7, the escape platform was positioned in a new (opposite) quadrant and rats were tested in a four-trial paradigm, as described above. For this reverse learning task, distance and time spent swimming in each quadrant were recorded.

\section{Histological procedures}

The day after the last testing session, five rats of each experimental group were perfused transcardially with fixative ( $4 \%$ paraformaldehyde) under deep pentobarbital anesthesia. Brains were removed and placed in fixative, whereas excised adrenals and thymi were maintained on salinesoaked filter papers until weighing. After $\sim 4$ weeks in fixative, brains were split into two hemispheres by a midsagittal section and processed for stereology, according to the procedure described previously by Keuker et al. (2001). Briefly, they were included in glycolmethacrylate (Tecnovit 7100; Heraeus Kulzer, Werheim, Germany) and every other microtome-cut section $(30 \mu \mathrm{m})$ was then collected on a gelatinized slide, stained with Giemsa, and mounted with Entellan New (Merck, Darmstadt, Germany). The shrinkage factor was calculated according to Madeira et al. (1990).

Region and layer boundaries. We analyzed four regions of the PFC (Vogt et al., 2004), including the three areas of the mPFC [cingulate (Cg), prelimbic (PL), and infralimbic (IL) cortices] and one just caudal to them [retrosplenial cortex (RSC)]; the older nomenclature of Zilles and Wree (1995) was adopted for easier reference to the most widely used atlases and previously reported data. The entire motor cortex (MC), comprising areas M1, M2, and M3, and the hippocampal formation (HF) were also measured. The above mentioned regions were outlined according to the atlas of Paxinos and Watson (1998), based on noticeable cytoarchitectural differences (Palomero-Gallagher and Zilles, 2004; Vogt et al., 2004). Each cortical region was further divided parallel to the surface in three easily recognizable levels (layer I, layer II, and layers III-VI), based on cell packing. The third level was considered as a whole, because a clear boundary between its layers could not be found in the PFC, especially in the more ventral regions. The HF was analyzed according to its main anatomical divisions: dentate gyrus (including hilus, granule cell layer, and molecular layer), CA3, and CA1 (strata oriens, pyramidale, and radiatum).

Stereological procedures. Volume and neuronal number estimations were performed using StereoInvestigator software (MicroBrightField, Williston, VT) and a camera (DXC390; Sony, Tokyo, Japan) attached to a motorized microscope (Axioplan 2; Zeiss, Oberkochen, Germany).

Cavalieri's principle (Gundersen et al., 1988) was used to assess the volume of each region. Briefly, every 8th (for IL and PL), 12th (for Cg), 16th (for RSC), 20th (for HF), and 22nd (for MC) section was used and its cross-sectional area was estimated by point counting at a final magnification of $112 \times$. For this, we randomly superimposed onto each area a test point grid in which the interpoint distance, at tissue level, was as follows: (1) $75 \mu \mathrm{m}$ for IL levels 1-2, (2) $100 \mu \mathrm{m}$ for IL level 3 and PL levels $1-2$, (3) $150 \mu \mathrm{m}$ for PL level 3, levels 1-2 of Cg and RSC, and the three layers of the dentate gyrus, (4) $250 \mu \mathrm{m}$ for level 3 of Cg and RSC, level 2 of MC, and the three layers of CA1 and CA3, and (5) $350 \mu \mathrm{m}$ for level 3 of MC. The volume of the region of interest was calculated from the number of points that fell within its boundaries and the distance between the systematically sampled sections.

Average cell numbers were estimated using the optical fractionator method, as described previously (West et al., 1991). Briefly, the following sampling scheme was used: (1) sections $8,12,16,20$, or 22, depending on the region being analyzed, were measured; (2) beginning at a random starting position, a grid of virtual three-dimensional boxes $(30 \times 30 \times 15$ 
$\mu \mathrm{m}$ ) that were equally spaced (the same grid as that for the volume estimations) was superimposed within the predefined borders; and (3) neurons were counted whenever their nucleus came into focus within the counting box. Neurons were differentiated from other cells on the basis of nuclear size (larger in neurons than in glia cells), a prominent nucleolus, and the shape of their perikarya attributable to dendritic emergence (Peinado et al., 1997).

Coefficients of error were automatically computed by the software according to the formulas of Gundersen et al. (1999) for cell numbers and Gundersen and Jensen (1987) for volume estimations.

\section{Statistical analysis}

Results are expressed as group means \pm SE. Working memory task performance was analyzed using repeated-measures ANOVA on the average results (across the $4 \mathrm{~d}$ ) of each trial. One-way ANOVA was performed on the results of the sixth day to check whether basal learning condition was similar before behavioral shifting. Reversal learning task and stereology results were also analyzed using one-way ANOVA. Tukey's honestly significant difference test was applied post hoc to test whether means differed significantly from each other (pairwise comparisons). Differences were considered to be significant if $p<0.05$.

\section{Results}

\section{Biometric parameters and hormonal determinations}

The efficacy of the various hormonal manipulations was proven by their effects on body weight (Fig. 1A). Repeated-measures ANOVA revealed a significant effect of both time after start of treatment $\left(F_{(5,180)}=949.004 ; p<0.001\right)$ and experimental group $\left(F_{(3,36)}=177.183 ; p<0.001\right)$, as well as an interaction between these two factors $\left(F_{(15,180)}=667.651 ; p<0.001\right)$. Compared with controls (and overall), both ADX and CORT-treatment groups resulted in a decreased body weight gain, which was more prominent in the latter; in contrast, DEX-treated rats showed a net weight loss.

ANOVA revealed a significant effect of treatment on thymus/ body weight ratio at the time of autopsy $\left(F_{(3,36)}=214.688 ; p<\right.$ $0.001)$. Compared with controls, the thymus/body weight ratio was significantly increased in ADX animals $(p<0.001)$ and significantly decreased $(p<0.001)$ in rats exposed to either CORT $(p<0.001)$ or DEX (Fig. $1 B)$.

ANOVA also revealed a significant effect of treatment on adrenal weight $\left(F_{(2,12)}=46.906 ; p<0.001\right)$. Compared with controls, adrenal weight was significantly decreased in CORT- (41\%; $p<0.001)$ and DEX- $(55 \% ; p<0.001)$ treated rats; adrenal weights did not differ between the latter groups (Fig. 1C).

Repeated-measures ANOVA showed that all treatments induced significant changes in plasma CORT levels $\left(F_{(3,36)}=\right.$ 208.625; $p<0.001$ ) (Fig. 1D). Although CORT was undetectable in the serum of both ADX and DEX-treated animals (as expected), animals treated with CORT displayed five to eight times higher circulating levels of the hormone (day and night), compared with controls (CORT vs CON, vs DEX, and vs ADX, $p<$ 0.001; CON vs DEX, $p=0.027$, vs ADX, $p=0.01)($ Fig $1 D)$.

\section{Behavioral data}

Spatial working memory task

The analysis of the distance-swum learning curves in the spatial working memory task (Fig. $2 B$ ) revealed a significant effect of bars represent SEM.
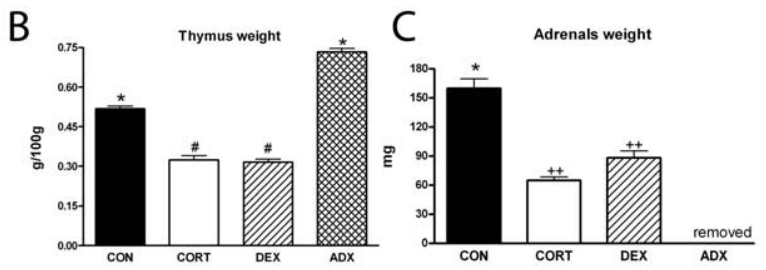

Serum corticosterone measurements :00 A.M.
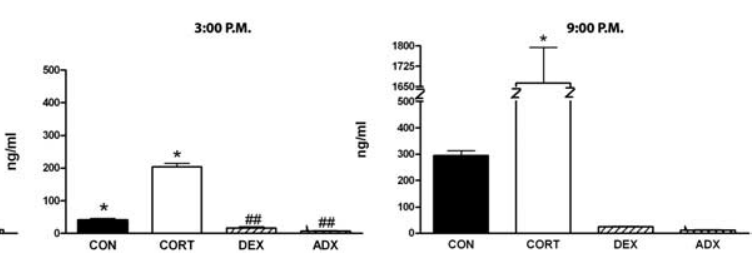

e course of the study. $B$, Thymus/body weight ratios. C, Adrenal weights. D, Serum corticosterone levels with respect to time of day (left, $1 \mathrm{~h}$ after lights on, 9:00 A.M.; middle, middle of the daily light/dark cycle, 3:00 P.M.; right, $1 \mathrm{~h}$ after lights out, 9:00 P.M.) after 4 weeks of exposure to the various tents. CORT and DEX were injected $1 \mathrm{~h}$ before lights off; $\mathrm{CON}$ and ADX animals received vehicle injections. ${ }^{*} p<0.05$ versus all other groups; ${ }^{\#} p<0.05$ versus CON and versus ADX; ${ }^{\#} p<0.05$ versus $\mathrm{CON}$ and versus CORT; ${ }^{++} p<0.05$ versus CON. Error

treatment $\left(F_{(3,36)}=3.074 ; p=0.04\right)$. DEX-treated rats showed impaired learning ability, swimming longer distances on the second (55\% more), third ( $92 \%$ more), and fourth (74\% more) trials compared with controls $(p=0.022)$ but not ADX rats, which nevertheless showed learning curves similar to those observed for controls. The performance of CORT-treated rats did not differ significantly from any of the other experimental groups.

\section{Reverse learning task}

On the second day of the reference memory task (day 5), DEXtreated rats were still performing worse than both CON and CORT-treated animals, whereas ADX were not different from any other group (CON, $245 \pm 33 \mathrm{~cm}$; CORT, $251 \pm 27 \mathrm{~cm}$; DEX, $\left.420 \pm 50 \mathrm{~cm} ; \mathrm{ADX}, 356 \pm 55 ; F_{(3,36)}=3.87 ; p=0.016\right)$. The platform was kept in the same position for another day (day 6 ) to ensure that all animals had learned the platform position and were performing equally well on this test.

All rats had learned the platform position equally well by the day before the reverse task (day 6) was performed: ANOVA on distance swum revealed no between-group differences (CON, $243 \pm 31 \mathrm{~cm}$; CORT, $208 \pm 30$; DEX, $295 \pm 42 \mathrm{~cm}$; ADX, $260 \pm$ $\left.46 \mathrm{~cm} ; F_{(3,36)}=1.264 ; p=0.301\right)$.

Analysis of the percentage of distance swum in each quadrant during the course of the reverse learning test (Fig. 2C) failed to reveal differences between treatment groups on either of the neutral quadrants $\left(\mathrm{S}, F_{(3,36)}=0.908, p=0.447 ; \mathrm{N}, F_{(3,36)}=0.500\right.$, $p=0.685)$. However, a significant effect of treatment was found for quadrants $\mathrm{E}$ (position of platform during preceding $3 \mathrm{~d}$ ) and $\mathrm{W}$ (new location of the platform) $\left(\mathrm{E}, F_{(3,36)}=13.143, p<0.001\right.$; $\left.\mathrm{W}, F_{(3,36)}=14.172, p<0.001\right)$. Controls promptly learned the location of the new platform, compared with all of the other groups, as shown by the simultaneous decreased distance swum in quadrant $\mathrm{E}$ ( $55 \%$ less vs $\mathrm{ADX}, p=0.0014 ; 60 \%$ less vs CORT, $p=0.002 ; 70 \%$ less vs DEX, $p<0.001)$ and increased distance in quadrant $\mathrm{W}$ (ADX, $p=0.027$; CORT, $p=0.015$; DEX, $p<$ $0.001)$. In contrast, DEX-treated rats were more persistent in searching the platform on its previous location (quadrant E) compared with controls $(p<0.001)$ and $\operatorname{ADX}(p=0.024)$; consequently, they swam lesser distances than any other group on 
A

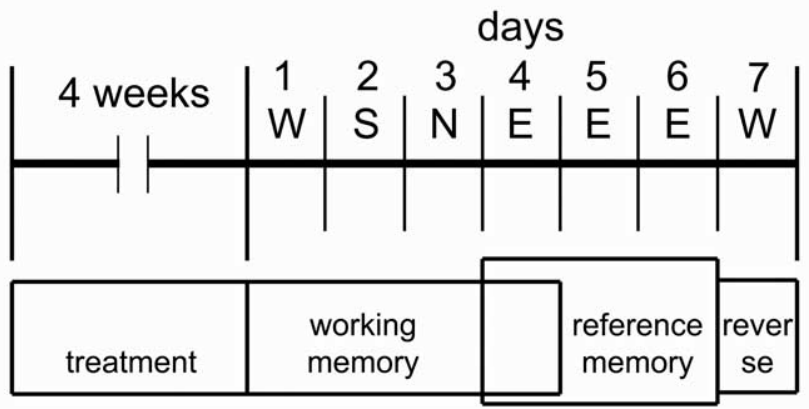

B

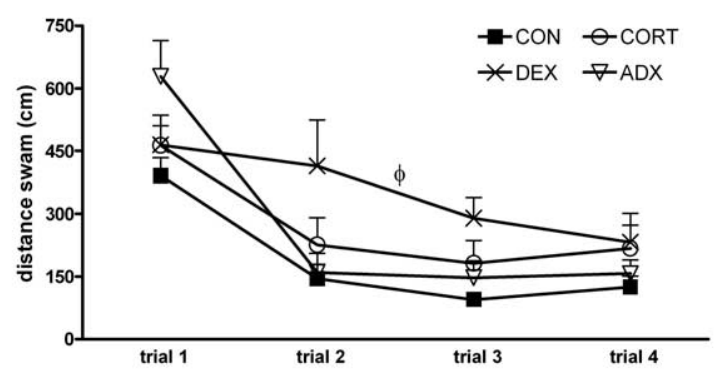

C

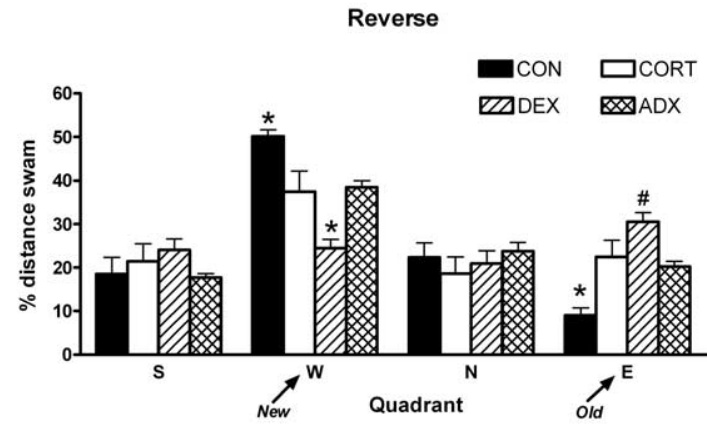

Figure 2. Behavioral data. $\boldsymbol{A}$, Schematic representation of the experimental procedure. The position of the platform on each day is also indicated (above). Note that, during the $3 \mathrm{~d}$ allowed for memory consolidation (days $4-6$ ), the platform was kept at the same position. $\boldsymbol{B}$, Learning curve in the working memory task. The higher distances swum by the DEX-treated rats is easily appreciated. C, Results from the reverse task experiment: average distance swum on the four trials in each imaginary quadrant is given as a percentage of the total distance swum. ${ }^{*} p<0.05$ versus all other groups; ${ }^{\#} p<0.05$ versus $\mathrm{CON}$ and versus $\mathrm{ADX} ;{ }^{++} p<0.05$ versus CON. Error bars represent SEM.

the newer location, $\mathrm{W}$ (vs CON, $p<0.001$; vs ADX, $p=0.006$; vs CORT, $p=0.011$ ).

\section{Volumes and neuronal numbers}

The shrinkage factor was calculated as 1.08, 1.07, 1.04, and 1.11, respectively, for controls, CORT, DEX, and ADX treatment groups. The slight variations found in DEX- and ADX-treated groups are consistent with the expected reduced (DEX-induced) or increased (ADX-induced) water content of brain tissue.

\section{Cingulate cortex}

Volumes of layer I of the anterior cingulate cortex (ACC) were not significantly different across the four treatment groups $\left(F_{(3,16)}=0.164 ; p=0.919\right)$ (Fig. $\left.3 B\right)$. In contrast, there was a significant effect of treatment on the volume of layer II $\left(F_{(3,16)}=\right.$ 23.585; $p<0.001$ ) (Fig. 3C) and layers III-VI $\left(F_{(3,16)}=16.054\right.$; $p<0.001$ ) (Fig. 3D). In CORT- and DEX-treated rats, the volumes of these layers were significantly reduced (between 10 and $25 \%$ ) compared with those of ADX (layer II CORT, $p<0.001$, DEX, $p<0.001$; layer III-VI CORT, $p=0.001$, DEX, $p<0.001)$ and control animals (layer II CORT, $p<0.001$, DEX, $p<0.001$; layer III-VI CORT, $p=0.009 ; \mathrm{DEX}, p=0.002)$. No significant differences were found between the volumes of ADX and control rats or between the volumes of CORT- and DEX-treated animals.

The number of neurons on layer II was significantly influenced by treatment $\left(F_{(3,16)}=6.925 ; p=0.003\right)$ (Fig. 3E). Post hoc comparisons revealed that cell numbers in layer II of ACC in DEX-treated rats were significantly reduced (by $20 \%$ vs CON, $p=0.006 ; 16 \%$ vs CORT, $p=0.043 ; 20 \%$ vs ADX, $p=0.006)$. No differences were observed in the number of neurons in layers III-VI $\left(F_{(3,16)}=1.209 ; p=0.338\right)$. (Fig. $\left.3 F\right)$

\section{Prelimbic cortex}

Volumetric analysis in the prelimbic cortex revealed a significant effect of treatment on all layers (layer I, $F_{(3,16)}=3.519, p=0.039$; layer II, $F_{(3,16)}=8.586, p=0.001$; layers III-IV, $F_{(3,16)}=4.757$, $p=0.015$ ) (Fig. $3 B-D$ ). The volume of layer II in DEX-treated rats was reduced by some $18 \%$ versus controls $(p=0.008)$ and ADX animals ( $p=0.003)$, whereas this measure was $15 \%$ less in CORT-treated versus ADX rats $(p=0.025)$; the latter did not differ significantly from control values. In both layers I and IIIVI, significant differences were only detectable between the volumes of DEX-treated and ADX rats (layer I, $p=0.039$; layers III-VI, $p=0.012$ ). Again, no significant differences were found between the volumes of ADX and control rats or between the volumes of CORT- and DEX-treated animals.

ANOVA revealed an effect of treatment in neuronal numbers in layer II of the prelimbic cortex $\left(F_{(3,16)}=3.948 ; p=0.028\right)$. A significantly smaller number of neurons ( $23 \%$ fewer, $p=0.002$ ) was observed in layer II of DEX-treated versus control rats; neuron numbers in this layer did not otherwise differ between the various experimental groups (Fig. $3 E$ ). Treatment per se did not affect the number of neurons in layers III-VI of the prelimbic cortex $\left(F_{(3,16)}=0.780 ; p=0.522\right)$ (Fig. $\left.3 F\right)$.

\section{Infralimbic cortex}

Treatment proved to be a significant factor with respect to the volumes of layers I and II of the infralimbic cortex (layer I, $F_{(3,16)}=4.673, p=0.016$; layer II, $F_{(3,16)}=7.047, p=0.003$ ) (Fig. $3 B, C)$. Within the most superficial layer, the only significant difference found was between DEX-treated and ADX animals $(p=0.032)$. Conversely, the volume of layer II in both DEX-and CORT-treated rats was reduced compared with that in controls (DEX, $p=0.046$; CORT, $p=0.041$ ) and ADX rats (DEX, $p=0.015$; CORT, $p=0.013)$. The volumes of layers III-VI did not differ significantly in any of the experimental groups $\left(F_{(3,16)}=2.765 ; p=0.076\right)$ (Fig. 3D).

The number of neurons in layer II of DEX-treated rats was significantly reduced $\left(F_{(3,16)}=4.005 ; p=0.026\right)$ compared with controls (23\% lower, $p=0.041)$ and ADX animals (12\% lower, $p=0.049$ ) (Fig. 3E). No other differences in the number of layer II neurons were observed, regardless of treatments. Neuronal numbers of layers III-VI were similar between all groups $\left(F_{(3,16)}=0.314 ; p=0.815\right)($ Fig. $3 F)$.

\section{Retrosplenial cortex}

Volumes of layers I, II, and II-VI of the RSC did not differ significantly across the four treatment groups (layer I, $F_{(3,16)}=1.106$, $p=0.37$; layer II, $F_{(3,16)}=1.734, p=0.20$; layers III-VI, $F_{(3,16)}=$ 2.045, $p=0.148$ ) (Fig. $3 B-D$ ). Likewise, no significant effects of 
treatment were found with respect to neuronal numbers in layers II $\left(F_{(3,16)}=0.164\right.$; $p=0.91)$ and III-VI $\left(F_{(3,16)}=0.466 ; p=\right.$ 0.710 ) of the RSC (Fig. $3 E, F)$.

\section{Motor cortex}

The volumes of MC layers I, II, and III-VI did not differ between treatment groups (layer I, $F_{(3,16)}=0.915, p=0.456$; layer II, $F_{(3,16)}=0.738, p=0.544$; layers III-VI, $F_{(3,16)}=1.002, p=0.418$ ) (Fig. $3 B-D$ ). Likewise, none of the treatments exerted a significant effect on neuronal numbers in layers II $\left(F_{(3,16)}=0.084 ; p=0.968\right)$ and III-VI $\left(F_{(3,16)}=0.203 ; p=0.893\right)$ in this region (Fig. $3 E, F$ ).

\section{Hippocampal formation}

Volumetric analysis in the dentate gyrus revealed a significant effect of treatment on all layers (molecular layer, $F_{(3,16)}=4.073$, $p=0.025$; granule cell layer, $\mathrm{F}_{(3,16)}=6.286$, $p=0.005$; hilus, $\left.F_{(3,16)}=34.349, p<0.001\right)$ (Fig. $4 A$ ). The only detectable difference in the molecular layer was a reduction in the volumes of DEX-treated rats versus controls ( $p=0.032)$; in the granule cell layer, the only significant volume reduction found was between the ADX and control $(p=0.005)$ and the ADX and CORT-treated ( $p=0.03$ ) groups. Hilus volume was reduced in all groups compared with controls $(p<0.001$ in all cases); in addition, DEX-treated rats showed significantly different volumes compared with CORT-treated ( $p=0.017$ ) and $\operatorname{ADX}(p=0.022)$ animals. The number of neurons in the granule cell layer of DEX-treated rats was significantly reduced compared with controls $\left(20 \%\right.$ lower, $\left.F_{(3,16)}=13.083, p=0.001\right)$;

ADX animals showed significantly fewer neurons than controls $(25 \%$ lower, $p<0.001)$ and CORT-treated rats $(14 \%$ lower, $p=0.039$ ) (Fig. $4 D$ ).

Treatment with DEX led to significant volume changes in the of strata of CA3 (stratum oriens, $F_{(3,16)}=15.789, p<0.001$; pyramidal cell layer, $F_{(3,16)}=6.031, p=0.006$; stratum radiatum, $F_{(3,16)}=8.342, p=0.006$ ) (Fig. $4 B$ ). Within the most superficial layer, DEX caused a significant volume reduction compared with other treatments (vehicle, $p<0.001$; CORT, $p=0.003$; $\mathrm{ADX}, p=$ $0.002)$; volumetric differences in the pyramidal cell layer and stratum radiatum were observed after DEX treatment with respect to controls (pyramidal cell layer, $p=0.010$; stratum radiatum, $p=0.004$ ) and ADX (pyramidal cell layer, $p=0.011$; stratum radiatum, $p=0.003)$. In addition, the number of CA3 pyramidal neurons was reduced in DEX-treated rats $\left(F_{(3,16)}=\right.$ 5.633; $p<0.008)$ compared with control $(p=0.036)$ and ADX $(p=0.032)$ rats (Fig. $4 D)$.

The volumes of the stratum oriens, pyramidal cell layer, and stratum radiatum of the CA1 did not differ between treatment groups (stratum oriens, $F_{(3,16)}=0.353, p=0.787$; pyramidal cell layer, $F_{(3,16)}=1.267, p=0.319$; stratum radiatum, $F_{(3,16)}=$ 0.053, $p=0.983$ ) (Fig. 4C). Likewise, none of the treatments exerted a significant effect on neuronal numbers within the CA1 subfield $\left(F_{(3,16)}=0.140 ; p=0.934\right)$.

Precision of the estimates

The coefficients of error for volume and cell number estimates were all within the optimal range $(<0.10)$, as detailed in supplemental Table 1 (available at www.jneurosci.org as supplemental material).

\section{Discussion}

Working memory, defined as the ability to transiently retain information that may be used to guide subsequent actions (Goldman-Rakic, 1995), is a characteristic function of the PFC. This concept, originally based on studies in humans and other primates (Greenlee et al., 2000; Petrides, 2000; Rowe and Passingham, 2001), has been shown to apply to rats using a variety of rigorous tests, including the radial-arm maze (Fritts et al., 1998), a matching-to-sample task on a T-maze (Dias and Aggleton, 2000), a delayed-response task (Mizoguchi et al., 2000), or the spatial working memory version of the Morris water maze (Kesner, 2000). The key feature of these tests is that the information presented is manipulated before the subject is tested for its ability to make an appropriate behavioral response; these tasks 
A

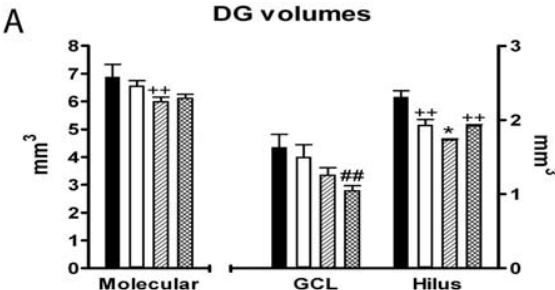

CA1 volumes
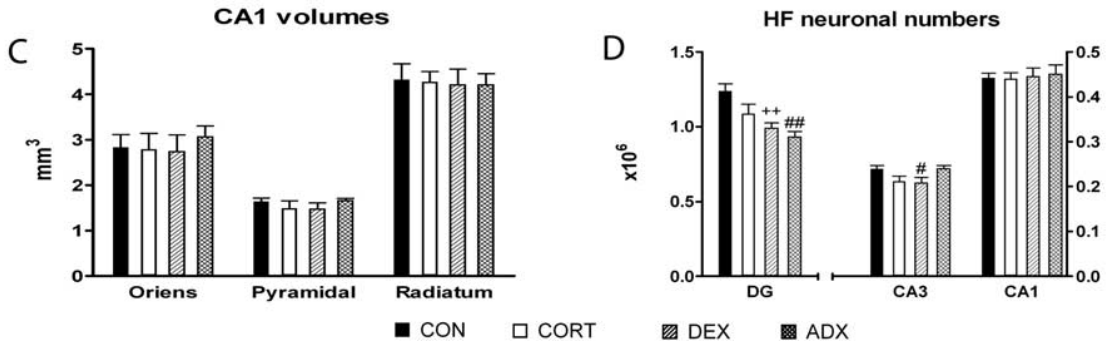

Figure 4. Stereological data from the hippocampal formation. $\boldsymbol{A}-\boldsymbol{C}$, Mean volumes of the different layers of the dentate gyrus, $C A 3$, and CA1 regions, respectively. $D$, Estimated number of neurons in the granule [dentate gyrus (DG)] and pyramidal (CA3 and (A1) layers. Note that, in $\boldsymbol{A}$ and $\boldsymbol{D}$, the numerical values for the leftward bars (molecular layer and granule cell layer, respectively) should be read off against the axis on the left, whereas all other data should be read off against the right one. ${ }^{*} p<0.05$ versus every other group; ${ }^{\#} p<0.05$ versus $\mathrm{CON}$ and versus ADX; ${ }^{++} p<0.05$ versus $\mathrm{CON} ;{ }^{\# \#} p<0.05$ versus CON and versus CORT. Error bars represent SEM.

therefore contrast sharply with simple short-term memory tasks involving recognition and recall, abilities that are spared from impairment after PFC damage (Lacroix et al., 2002).

The spatial working memory version of the water maze was chosen to assess working memory performance in this study because it uses the same experimental set up and recruits a similar range of skills (swimming, visuospatial orientation) as does the Morris water maze, the classical test of hippocampus-dependent spatial reference memory. In the present study, we found that spatial working memory is (1) unaffected in corticosteroid-free (ADX) rats whose MR and GR remain unoccupied, (2) severely impaired in rats with selective and chronic activation of GR (through the administration of DEX), and (3) not affected by chronic treatment with the mixed MR/GR agonist CORT.

The likely insensitivity of the Morris water maze test of working memory to discriminate impairments in PFC-dependent working memory from deficits in PFC-independent short-term memory (Lacroix et al., 2002) may be overcome by applying tests of response flexibility. In such tests, subjects with PFC damage fail to perceive and adapt to new informational cues and persistently use behavioral strategies that are based on "old rules" that are no longer applicable (Salazar et al., 2004). A number of paradigms may be used to test behavioral adaptation, including the operant chamber (Salazar et al., 2004), T-maze (Dias and Aggleton, 2000), and Morris water maze (Lacroix et al., 2002). Using the last of these, we found that $\mathrm{MPFC}$ function is significantly disrupted in rats that had been ADX or exposed to chronic corticosteroid (CORT or DEX) treatments; of these three treatments, the GR agonist DEX caused the greatest impairment of PFC-dependent function.

Interesting insights into the role of corticosteroids in PFCdependent functions can be gleaned by considering the combined results obtained in the spatial memory and reverse learning tasks. The finding that ADX and adrenal-intact control rats perform equally well and excel over DEX-treated subjects on the spatial working memory test could be interpreted to suggest that corticosteroids are not essential for mPFC function. This view is re- futed by the observation that ADX animals show impaired performance on the reverse learning task; this demonstrates that corticosteroid receptor occupation is required for optimal behavioral flexibility. A similar conclusion was reached in another study, which showed the essential role of glucocorticoids in the delayed non-matchto-sample task, another test of mPFCdependent function (Mizoguchi et al., 2004).

The PFC and hippocampus share several similarities and roles: (1) both participate in regulation of the HPA axis (Herman et al., 1996; Sullivan and Gratton, 2002), (2) both express MR and GR (Van Eekelen and de Kloet, 1992; Diorio et al., 1993; Kawata et al., 1998; Patel et al., 2000), and (3) both are involved in the processing of spatial information (Lee and Kesner, 2003). An additional interesting observation is that stress influences the induction of long-term potentiation (LTP) and long-term depression via a direct pathway between the PFC and hippocampus (Jay et al., 1995; Rocher et al., 2004). In contrast, the hippocampus displays higher MR and GR densities than the PFC (Kawata et al., 1998) and is more responsive to corticosteroids than the cortex (Kitchener et al., 2004). Here, it is relevant to mention that, although the precise distribution of MR and GR within the layers of the PFC of rodents is not known, available evidence suggests that (1) layers II/III of the PFC seems to be endowed with relatively high levels of both receptor [for MR, see Ahima et al. (1991) and van Eekelen et al. (1991); for GR, see Ahima and Harlan (1990), Cintra et al. (1994), and Morimoto et al. (1996) ], and (2) there is an overall predominance of GR over MR in cortical structures (Ahima et al., 1990, 1991; Roland et al., 1995). We were thus prompted to compare the presently obtained data on the mPFC with those available for the hippocampus in which similar experimental paradigms were used. Notably, chronic DEX treatment, shown to impair PFC-dependent working memory and behavioral flexibility in this study, also impairs spatial reference memory, a function dependent of hippocampal integrity (our unpublished observations). Similarly, chronic CORT administration, which is known to interfere with hippocampal-dependent tasks (Coburn-Litvak et al., 2003), also reduces performance on tasks ascribed to the $\mathrm{mPFC}$ (present study). Last, ADX rats show deficits in tests of reference memory (Vaher et al., 1994; Conrad et al., 1997) and, as shown herein, display impaired behavioral flexibility despite an intact spatial working memory. By consolidating all of these findings, we now suggest that GR-activating corticosteroids (DEX or high CORT levels) are causally related to working memory deficits and that MR occupation (by basal CORT levels) is crucial for optimal $\mathrm{mPFC}$ function; this interpretation concords with current views on the dichotomous roles of MR and GR in the regulation of hippocampal structure and function (Sousa et al., 1999).

Our study also provides evidence for corticosteroid-induced changes in mPFC structure. With the aid of stereological tools, we present the first demonstration of DEX-induced neuronal loss in layer II of all $\mathrm{mPFC}$ regions; the fact that no other layer is affected indicates that the glucocorticoid acts in a highly specific manner. Importantly, DEX did not induce neuronal loss in the retrosple- 
nial cortex; this area, which is endowed with corticosteroid receptors (Roland et al., 1995; Kawata et al., 1998; Patel et al., 2000), represents the posterior extension of the cingulate cortex and provides guidance information that is crucial for the performance of spatial reference and working memory tasks (Vann and Aggleton, 2004). It is also notable that structural parameters within the motor cortex, a nonlimbic region, are not affected by chronic DEX treatment.

In contrast to DEX (a GR-selective agonist), high levels of CORT (which saturates GR but also activates MR) (Reul and de Kloet, 1985; Spencer et al., 1990) did not cause a significant reduction in mPFC neuron numbers. This observation is similar to that made previously in the hippocampal dentate gyrus (Sousa et al., 1999) and reproduced herein and accords with other findings that the neurotoxic actions of GR ligands can be attenuated by concomitant activation of MR (Sousa et al., 1999; Almeida et al., 2000; Crochemore et al., 2005). Nevertheless, it should be noted that other area-specific factors are likely to play a role in determining the survival of specific cell types. As an example, although ADX leads to severe neuronal death in the hippocampus (Sloviter et al., 1989; Hu et al., 1997; Sousa et al., 1997), it does not lead to neuronal loss in the mPFC. From this, it follows that the mechanisms leading to ADX-induced impairments in PFC-dependent cognitive function are not likely to involve atrophy of PFC neurons; rather, impaired function may result from alterations to the afferent connections to the PFC, as discussed below.

After correcting for differential shrinkage, our results show that both DEX and CORT resulted in significant reductions in mPFC volumes, particularly in layer II. Although volumetric reductions in DEX-treated animals may be partially ascribed to decreased cell numbers, other mechanisms seem to be implicated in the CORT-induced changes observed. Our current hypothesis is that CORT leads to atrophy of the dendritic trees that abound in this area. This view is consonant with reports that chronic exposure to CORT (Wellman, 2001) and stress (Radley et al., 2004) leads to a retraction of the apical trees of PFC layer II/III pyramidal cells; in a more recent study, Radley et al. (2005) demonstrated that chronic stress induces a significant loss of spines in these neurons. Moreover, the selective hyperphosphorylation of ERK1/2 (extracellular signal-regulated protein kinases 1/2) in dendrites of the higher prefrontocortical layers after exposure of rats to chronic stress has been linked to stress-associated dendritic atrophy (Trentani et al., 2002).

The particular sensitivity of mPFC layer II to prolonged hypercortisolemia, as revealed by our stereological measurements, is striking. Because this layer represents the main receptive field of the mPFC, it would appear that deafferentation of this layer might trigger both the structural changes and the behavioral deficits seen after alterations in the corticosteroid milieu, an interpretation supported by the observation that synaptic contacts are essential for the shaping and reorganization of dendritic trees (Mizrahi and Libersat, 2002). As alluded to earlier, the vulnerability of mPFC layer II cells to glucocorticoids is likely to result from changes in other glucocorticoid target areas. In addition to the hippocampus, other limbic structures such as the mediodorsal nucleus of the thalamus, the ventral tegmental area (VTA), and the amygdala also project to this area; although nothing is known about how corticosteroids influence VTA and thalamic architecture, recent studies have shown that corticosteroid effects on PFC function involve activation of amygdaloid neurons (Roozendaal et al., 2004). Interestingly, recent studies have shown that corticosteroids/stress also induces structural changes in the dendrites of amygdalar neurons (Vyas et al., 2002) and that stress contemporaneously inhibits LTP in the basolateral amygdala-mPFC pathway (Maroun and Richter-Levin, 2003).

Together, these results call for a shift in the present focus on the effects of corticosteroid-induced plasticity in the hippocampus to a more systems-based approach in which interactions between corticosteroid-sensitive brain areas are analyzed. The present results provide a morphological basis for how corticosteroid status (and presumably stress) can impact working memory; they contribute to our increased understanding of the neurobiological bases of a number of disease states in which PFC dysfunction is implicated (Lewis et al., 2004; Monchi et al., 2004; Shad et al., 2004); in particular, these findings may be relevant to depression (cf. Rogers et al., 2004). Indeed, the presently described corticosteroid-induced damage to the mPFC fits with previous postmortem data from subjects with major depression and bipolar disorder (Rajkowska, 2000). That work revealed specific histopathological changes (including cell atrophy and the loss of glia but not neurons) in the dorsolateral PFC, the human homolog of the rodent $\mathrm{mPFC}$.

\section{References}

Ahima RS, Harlan RE (1990) Charting of type II glucocorticoid receptorlike immunoreactivity in the rat central nervous system. Neuroscience 39:579-604.

Ahima R, Krozowski Z, Harlan R (1991) Type I corticosteroid receptor-like immunoreactivity in the rat CNS: distribution and regulation by corticosteroids. J Comp Neurol 313:522-538.

Almeida OF, Conde GL, Crochemore C, Demeneix BA, Fischer D, Hassan AH, Meyer M, Holsboer F, Michaelidis TM (2000) Subtle shifts in the ratio between pro- and antiapoptotic molecules after activation of corticosteroid receptors decide neuronal fate. FASEB J 14:779-790.

Altamura AC, Boin F, Maes M (1999) HPA axis and cytokines dysregulation in schizophrenia: potential implications for the antipsychotic treatment. Eur Neuropsychopharmacol 10:1-4.

Barden N (2004) Implication of the hypothalamic-pituitary-adrenal axis in the physiopathology of depression. J Psychiatry Neurosci 29:185-193.

Bechara A, Tranel D, Damasio H, Damasio AR (1996) Failure to respond autonomically to anticipated future outcomes following damage to prefrontal cortex. Cereb Cortex 6:215-225.

Bechara A, Tranel D, Damasio H (2000) Characterization of the decisionmaking deficit of patients with ventromedial prefrontal cortex lesions. Brain 123:2189-2202.

Chao HM, Choo PH, McEwen BS (1989) Glucocorticoid and mineralocorticoid receptor mRNA expression in rat brain. Neuroendocrinology 50:365-371.

Cintra A, Zoli M, Rosen L, Agnati LF, Okret S, Wikstrom AC, Gustaffsson JA, Fuxe K (1994) Mapping and computer assisted morphometry and microdensitometry of glucocorticoid receptor immunoreactive neurons and glial cells in the rat central nervous system. Neuroscience 62:843-897.

Coburn-Litvak PS, Pothakos K, Tata DA, McCloskey DP, Anderson BJ (2003) Chronic administration of CORT impairs spatial reference memory before spatial working memory in rats. Neurobiol Learn Mem 80:11-23.

Colvin MK, Dunbar K, Grafman J (2001) The effects of frontal lobe lesions on goal achievement in the water jug task. J Cogn Neurosci 13:1129-1147.

Conrad CD, Lupien SJ, Thanasoulis LC, McEwen BS (1997) The effects of type I and type II corticosteroid receptor agonists on exploratory behavior and spatial memory in the Y-maze. Brain Res 759:76-83.

Cook SC, Wellman CL (2004) Chronic stress alters dendritic morphology in rat medial prefrontal cortex. J Neurobiol 60:236-248.

Corcoran C, Mujica-Parodi L, Yale S, Leitman D, Malaspina D (2002) Could stress cause psychosis in individuals vulnerable to schizophrenia? CNS Spectr 7:33-38.

Crochemore C, Lu J, Wu Y, Liposits Z, Sousa N, Holsboer F, Almeida OF (2005) Direct targeting of hippocampal neurons for apoptosis by glucocorticoids is reversible by mineralocorticoid receptor activation. Mol Psychiatry 10:790-798.

Cullinan WE, Herman JP, Battaglia DF, Akil H, Watson SJ (1995) Pattern and time course of immediate early gene expression in rat brain following acute stress. Neuroscience 64:477-505. 
de Bruin JP, Sànchez-Santed F, Heinsbroek RP, Donker A, Postmes P (1994) A behavioral analysis of rats with damage to the medial prefrontal cortex using the Morris water maze: evidence for behavioral flexibility, but not for impaired spatial navigation. Brain Res 652:323-333.

de Kloet ER, Vreugdenhil E, Oitzl MS, Joels M (1998) Brain corticosteroid receptor balance in health and disease. Endocr Rev 19:269-301.

Dias R, Aggleton JP (2000) Effects of selective excitotoxic prefrontal lesions on acquisition of nonmatching- and matching-to-place in the T-maze in the rat: differential involvement of the prelimbic-infralimbic and anterior cingulate cortices in providing behavioral flexibility. Eur J Neurosci 12:4457-4466.

Diorio D, Viau V, Meaney MJ (1993) The role of the medial prefrontal cortex (cingulate gyrus) in the regulation of hypothalamic-pituitaryadrenal responses to stress. J Neurosci 13:3839-3847.

Figueiredo HF, Bruestle A, Bodie B, Dolgas CM, Herman JP (2003) The medial prefrontal cortex differentially regulates stress-induced c-fos expression in the forebrain depending on type of stressor. Eur J Neurosci 18:2357-2364.

Fritts ME, Asbury ET, Horton JE, Isaac WL (1998) Medial prefrontal lesion deficits involving or sparing the prelimbic area in the rat. Physiol Behav 64:373-380.

Goldman-Rakic PS (1995) Architecture of the prefrontal cortex and the central executive. Ann NY Acad Sci 769:71-83.

Greenlee MW, Berg H, Stuhr V, Mergner T (2000) Visual search and visual working memory in patients with chronic focal cortical lesions. Vision Res 40:3759-3773.

Gundersen HJ, Jensen EB (1987) The efficiency of systematic sampling in stereology and its prediction. J Microsc 147:229-263.

Gundersen HJ, Bendtsen TF, Korbo L, Marcussen N, Moller A, Nielsen K, Nyengaard JR, Pakkenberg B, Sorensen FB, Vesterby A, West MJ (1988) Some new, simple and efficient stereological methods and their use in pathological research and diagnosis. APMIS 96:379-394.

Gundersen HJ, Jensen EB, Kieu K, Nielsen J (1999) The efficiency of systematic sampling in stereology—reconsidered. J Microsc 193:199-211.

Hannesson DK, Howland JG, Phillips AG (2004) Interaction between perirhinal and medial prefrontal cortex is required for temporal order but not recognition memory for objects in rats. J Neurosci 24:4596-4604.

Hata T, Okaichi H (2004) Medial prefrontal cortex and precision of temporal discrimination: a lesion, microinjection, and microdialysis study. Neurosci Res 49:81-89.

Herman JP (1993) Regulation of adrenocorticosteroid receptor mRNA expression in the central nervous system. Cell Mol Neurobiol 13:349-372.

Herman JP, Prewitt CM, Cullinan WE (1996) Neuronal circuit regulation of the hypothalamo-pituitary-adrenocortical stress axis. Crit Rev Neurobiol 10:371-394.

Hu Z, Yuri K, Ozawa H, Lu H, Kawata M (1997) The in vivo time course for elimination of adrenalectomy-induced apoptotic profiles from the granule cell layer of the rat hippocampus. J Neurosci 17:3981-3989.

Jay TM, Burette F, Laroche S (1995) NMDA receptor-dependent long-term potentiation in the hippocampal afferent fibre system to the prefrontal cortex in the rat. Eur J Neurosci 7:247-250.

Joel D, Tarrasch R, Feldon J, Weiner I (1997) Effects of electrolytic lesions of the medial prefrontal cortex or its subfields on 4 -arm baited, 8 -arm radial maze, two-way active avoidance and conditioned fear tasks in the rat. Brain Res 765:37-50.

Kawata M, Yuri K, Ozawa H, Nishi M, Ito T, Hu Z, Lu H, Yoshida M (1998) Steroid hormones and their receptors in the brain. J Steroid Biochem Mol Biol 65:273-280.

Kesner RP (2000) Subregional analysis of mnemonic functions of the prefrontal cortex in the rat. Psychobiology 28:219-228.

Keuker JI, Vollmann-Honsdorf GK, Fuchs E (2001) How to use the optical fractionator: an example based on the estimation of neurons in the hippocampal CA1 and CA3 regions of tree shrews. Brain Res Brain Res Protoc 7:211-221.

Kitchener P, Di Blasi F, Borrelli E, Piazza PV (2004) Differences between brain structures in nuclear translocation and DNA binding of the glucocorticoid receptor during stress and the circadian cycle. Eur J Neurosci 19:1837-1846.

Lacroix L, White I, Feldon J (2002) Effect of excitotoxic lesions of rat medial prefrontal cortex on spatial memory. Behav Brain Res 133:69-81.

Lee I, Kesner RP (2003) Time-dependent relationship between the dorsal hippocampus and the prefrontal cortex in spatial memory. J Neurosci 23:1517-1523.

Lewis DA, Cruz D, Eggan S, Erickson S (2004) Postnatal development of prefrontal inhibitory circuits and the pathophysiology of cognitive dysfunction in schizophrenia. Ann NY Acad Sci 1021:64-76.

Li L, Shao J (1998) Restricted lesions to ventral prefrontal subareas block reversal learning but not visual discrimination learning in rats. Physiol Behav 65:371-379.

Madeira MD, Pereira A, Cadete-Leite A, Paula-Barbosa MM (1990) Estimates of volumes and pyramidal cell numbers in the prelimbic subarea of the prefrontal cortex in experimental hypothyroid rats. J Anat 171:41-56.

Manes F, Sahakian B, Clark L, Rogers R, Antoun N, Aitken M, Robbins T (2002) Decision-making processes following damage to the prefrontal cortex. Brain 125:624-639.

Maroun M, Richter-Levin G (2003) Exposure to acute stress blocks the induction of long-term potentiation of the amygdala-prefrontal cortex pathway in vivo. J Neurosci 23:4406-4409.

Milner B, Petrides M, Smith ML (1985) Frontal lobes and the temporal organization of memory. Hum Neurobiol 4:137-142.

Mizoguchi K, Yuzurihara M, Ishige A, Sasaki H, Chui DH, Tabira T (2000) Chronic stress induces impairment of spatial working memory because of prefrontal dopaminergic dysfunction. J Neurosci 20:1568-1574.

Mizoguchi K, Ishige A, Aburada M, Tabira T (2003) Chronic stress attenuates glucocorticoid negative feedback: involvement of the prefrontal cortex and hippocampus. Neuroscience 119:887-897.

Mizoguchi K, Ishige A, Takeda S, Aburada M, Tabira T (2004) Endogenous glucocorticoids are essential for maintaining prefrontal cortical cognitive function. J Neurosci 24:5492-5499.

Mizrahi A, Libersat F (2002) Afferent input regulates the formation of distal dendritic branches. J Comp Neurol 452:1-10.

Monchi O, Petrides M, Doyon J, Postuma RB, Worsley K, Dagher A (2004) Neural bases of set-shifting deficits in Parkinson's disease. J Neurosci 24:702-710.

Morimoto M, Morita N, Ozawa H, Yokoyama K, Kawata M (1996) Distribution of glucocorticoid receptor immunoreactivity and mRNA in the rat brain: an immunohistochemical and in situ hybridization study. Neurosci Res 26:235-269.

Morris R (1984) Developments of a water-maze procedure for studying spatial learning in the rat. J Neurosci Methods 11:47-60.

Muller NG, Machado L, Knight RT (2002) Contributions of subregions of the prefrontal cortex to working memory: evidence from brain lesions in humans. J Cogn Neurosci 14:673-686.

Palomero-Gallagher N, Zilles K (2004) Isocortex. In: The rat nervous system, Ed 3 (Paxinos G, ed), pp 729-757. San Diego: Academic Press.

Patel PD, Lopez JF, Lyons DM, Burke S, Wallace M, Schatzberg AF (2000) Glucocorticoid and mineralocorticoid receptor mRNA expression in squirrel monkey brain. J Psychiatr Res 34:383-392.

Paxinos G, Watson C (1998) The rat brain in stereotaxic coordinates, Ed 4. San Diego: Academic.

Peinado MA, Quesada A, Pedrosa JA, Martinez M, Esteban FJ, Del Moral ML, Peinado JM (1997) Light microscopic quantification of morphological changes during aging in neurons and glia of the rat parietal cortex. Anat Rec 247:420-425.

Petrides M (2000) The role of the mid-dorsolateral prefrontal cortex in working memory. Exp Brain Res 133:44-54.

Radley JJ, Sisti HM, Hao J, Rocher AB, McCall T, Hof PR, McEwen BS, Morrison JH (2004) Chronic behavioral stress induces apical dendritic reorganization in pyramidal neurons of the medial prefrontal cortex. Neuroscience 125:1-6.

Radley JJ, Rocher AB, Miller M, Janssen WG, Liston C, Hof PR, McEwen BS, Morrison JH (2005) Repeated stress induces dendritic spine loss in the rat medial prefrontal cortex. Cereb Cortex, in press.

Rajkowska G (2000) Postmortem studies in mood disorders indicate altered numbers of neurons and glial cells. Biol Psychiatry 48:766-777.

Reul JM, de Kloet ER (1985) Two receptor systems for corticosterone in rat brain: microdistribution and differential occupation. Endocrinology 117:2505-2511

Reul JM, Bilang-Bleuel A, Droste S, Linthorst AC, Holsboer F, Gesing A (2000) New mode of hypothalamic-pituitary-adrenocortical axis regulation: significance for stress-related disorders. Z Rheumatol 59 [Suppl 2]:II/22-25.

Rocher C, Spedding M, Munoz C, Jay TM (2004) Acute stress-induced 
changes in hippocampal/prefrontal circuits in rats: effects of antidepressants. Cereb Cortex 14:224-229.

Rogers MA, Kasai K, Koji M, Fukuda R, Iwanami A, Nakagome K, Fukuda M, Kato N (2004) Executive and prefrontal dysfunction in unipolar depression: a review of neuropsychological and imaging evidence. Neurosci Res $50: 1-11$.

Roland BL, Krozowski ZS, Funder JW (1995) Glucocorticoid receptor, mineralocorticoid receptors, 11 beta-hydroxysteroid dehydrogenase- 1 and -2 expression in rat brain and kidney: in situ studies. Mol Cell Endocrinol 111:R1-R7.

Roozendaal B, McReynolds JR, McGaugh JL (2004) The basolateral amygdala interacts with the medial prefrontal cortex in regulating glucocorticoid effects on working memory impairment. J Neurosci 24:1385-1392.

Rowe JB, Passingham RE (2001) Working memory for location and time: activity in prefrontal area 46 relates to selection rather than maintenance in memory. NeuroImage 14:77-86.

Ryan MC, Sharifi N, Condren R, Thakore JH (2004) Evidence of basal pituitary-adrenal overactivity in first episode, drug naive patients with schizophrenia. Psychoneuroendocrinology 29:1065-1070.

Salazar RF, White W, Lacroix L, Feldon J, White IM (2004) NMDA lesions in the medial prefrontal cortex impair the ability to inhibit responses during reversal of a simple spatial discrimination. Behav Brain Res 152:413-424.

Shad MU, Muddasani S, Prasad K, Sweeney JA, Keshavan MS (2004) Insight and prefrontal cortex in first-episode schizophrenia. NeuroImage 22:1315-1320.

Shaw C, Aggleton JP (1993) The effects of fornix and medial prefrontal lesions on delayed non-matching-to-sample by rats. Behav Brain Res 54:91-102.

Sloviter RS, Valiquette G, Abrams GM, Ronk EC, Sollas AL, Paul LA, Neubort S (1989) Selective loss of hippocampal granule cells in the mature rat brain after adrenalectomy. Science 243:535-538.

Sousa N, Almeida OF (2002) Corticosteroids: sculptors of the hippocampal formation. Rev Neurosci 13:59-84.

Sousa N, Madeira MD, Paula-Barbosa MM (1997) Structural alterations of the hippocampal formation of adrenalectomized rats: an unbiased stereological study. J Neurocytol 26:423-438.

Sousa N, Paula-Barbosa MM, Almeida OF (1999) Ligand and subfield specificity of corticoid-induced neuronal loss in the rat hippocampal formation. Neuroscience 89:1079-1087.
Spencer RL, Young EA, Choo PH, McEwen BS (1990) Adrenal steroid type I and type II receptor binding: estimates of in vivo receptor number, occupancy, and activation with varying level of steroid. Brain Res 514:37-48.

Sullivan RM, Gratton A (2002) Prefrontal cortical regulation of hypothalamic-pituitary-adrenal function in the rat and implications for psychopathology: side matters. Psychoneuroendocrinology 27:99-114.

Trentani A, Kuipers SD, Ter Horst GJ, Den Boer JA (2002) Selective chronic stress-induced in vivo ERK1/2 hyperphosphorylation in medial prefrontocortical dendrites: implications for stress-related cortical pathology? Eur J Neurosci 15:1681-1691.

Vaher PR, Luine VN, Gould E, McEwen BS (1994) Effects of adrenalectomy on spatial memory performance and dentate gyrus morphology. Brain Res 656:71-78.

Van Eekelen JA, de Kloet ER (1992) Co-localization of brain corticosteroid receptors in the rat hippocampus. Prog Histochem Cytochem $26: 250-258$.

van Eekelen JA, Bohn MC, de Kloet ER (1991) Postnatal ontogeny of mineralocorticoid and glucocorticoid receptor gene expression in regions of the rat tel- and diencephalon. Brain Res Dev Brain Res 61:33-43.

Vann SD, Aggleton JP (2004) Testing the importance of the retrosplenial guidance system: effects of different sized retrosplenial cortex lesions on heading direction and spatial working memory. Behav Brain Res 155:97-108.

Vogt BA, Vogt L, Farber N (2004) Cingulate cortex and disease models. In: The rat nervous system, Ed 3 (Paxinos G, ed), pp 705-727. San Diego: Academic.

Vyas A, Mitra R, Shankaranarayana Rao BS, Chattarji S (2002) Chronic stress induces contrasting patterns of dendritic remodeling in hippocampal and amygdaloid neurons. J Neurosci 22:6810-6818.

Wellman CL (2001) Dendritic reorganization in pyramidal neurons in medial prefrontal cortex after chronic corticosterone administration. J Neurobiol 49:245-253.

West MJ, Slomianka L, Gundersen HJ (1991) Unbiased stereological estimation of the total number of neurons in the subdivisions of the rat hippocampus using the optical fractionator. Anat Rec 231:482-497.

Zilles K, Wree A (1995) Cortex: areal and laminar structure. In: The rat nervous system, Ed 2 (Paxinos G, ed), pp 649-685. San Diego: Academic. 